\title{
Involvement of the mitochondrial pathway and Bim/Bcl-2 balance in dihydroartemisinin-induced apoptosis in human breast cancer in vitro
}

\author{
HAITING MAO, HONGTAO GU, XUN QU, JINTANG SUN, BINGFENG SONG, \\ WENJUAN GAO, JIA LIU and QIANQIAN SHAO \\ Institute of Basic Medical Sciences, Qilu Hospital, Shandong University, Jinan, Shandong, P.R. China
}

Received August 27, 2012; Accepted October 5, 2012

DOI: $10.3892 /$ ijmm.2012.1176

\begin{abstract}
Dihydroartemisinin (DHA), a semi-synthetic derivative and active metabolite of artemisinin, has been shown to have profound anticancer potential in addition to its strong anti-malarial activity. The purpose of the present study was to thoroughly investigate the anti-neoplastic effects induced by DHA and to provide a molecular basis for the use of DHA in the treatment of breast cancer. Our results demonstrated that DHA could significantly inhibit the cell proliferation of breast cancer in a dose- and time-dependent manner that was associated with induced apoptosis and G0/G1 cell cycle arrest, and the half maximal inhibitory concentrations $\left(\mathrm{IC}_{50}\right)$ of DHA treatment were $60.03,33.86$ and $17.18 \mu \mathrm{M}$ for 24 , 48 and $72 \mathrm{~h}$, respectively. Moreover, the DHA treatment dramatically increased the protein expression of caspase-8, cleaved caspase-9, activated Bid and induced the release of cytochrome $c$ from mitochondria into the cytosol. In addition, the apoptotic action of DHA was associated with the increased expression of the pro-apoptotic gene Bim and a decreased expression of the anti-apoptotic gene Bcl-2. Therefore, the mitochondrial pathway is involved in the apoptosis of breast cancer cells induced by DHA and the imbalance of the Bim/ Bcl-2 interaction may promote the beneficial effect against breast cancer cells. Overall, our study provides the scientific rationale for the clinical usage of DHA for breast cancer.
\end{abstract}

\section{Introduction}

Breast cancer is a global health problem, representing the primary cause of cancer-related female mortality in developing countries (1). Treatment for breast cancer varies depending

Correspondence to: Professor Haiting Mao, Institute of Basic Medical Sciences, Qilu Hospital, Shandong University, 107 Wen Hua Xi Road, Jinan, Shandong 250012, P.R. China

E-mail: haitingmao@yahoo.com

Key words: dihydroartemisinin, breast cancer, proliferation, cell cycle, mitochondrial apoptosis, Bim, Bcl-2 on tumor stage and molecular characteristics. However, only $50-70 \%$ of patients receiving chemotherapy respond to firstline treatment (2). Almost all chemotherapeutic agents used in the treatment of breast cancer develop resistance mechanisms that are responsible for recurrence. Thus, discovering new chemotherapeutic drugs and treatment strategies is a challenging issue for the management of breast cancer.

Some natural plant compounds provide a potential source of chemotherapeutic agents and display potent anticancer activity; artemisinin (ART) and its derivatives are such promising natural compounds. ART is the active principle of the herbal drug Artemisia annua L. (commonly known as Qing $\mathrm{Hao}$ ) and has been used in traditional Chinese medicine for centuries. ART and its main active metabolites dihydroartemisinin (DHA) are highly effective anti-malarial drugs used as first-line therapeutics against malaria falciparum worldwide (3-7). Both ART and DHA are well-tolerated in human and animals with fewer adverse side-effects than any other antimalarial drug (8). DHA is a sesquiterpene lactone containing an endoperoxide trioxane moiety and has been widely used to treat malaria owing to its ability to generate reactive oxygen species (ROS) or carbon-centered radicals through cleavage of the endoperoxide bridge (8-11) and its extremely potent inhibition of the SERCA orthologue (PfATP6) of Plasmodium falciparum (12-14). Apart from the use in the treatment of malaria, more recent studies have shown that DHA also has profound antitumor activity both in vitro and in vivo, including in lung, ovarian, pancreatic, colon, breast, prostate, liver and brain cancer (15-22). It is believed that DHA exerts its cytotoxic and apoptotic effects by the generation of organic free radicals, resulting in the induction of ROS from the iron-or heme-mediated cleavage of endoperoxide bridge contained in DHA $(11,23)$. Some studies have also shown that DHA-induced apoptosis may be related to the p38 MAPK, NF-KB, hypoxia inducible factor- $1 \alpha$ (HIF-1 $\alpha)$, transferrin receptor, MEK/ERK inactivation and Bcl-2 family signaling pathway $(16,22,24)$. In addition, DHA seems to be able to bypass the multi-drug resistance (MDR) and presents similar anticancer potential in the parent and the resistant MDR cancer cells (25). However, the exact molecular mechanism by which DHA executes its anticancer effect is not fully understood. 
The present study was designed to further explore the underlying mechanism of DHA treatment against breast cancer cells in vitro from the standpoint of the proliferation inhibition and apoptosis signaling pathway. We found that DHA displayed cytotoxicities against the T-47D breast cancer cells by inhibiting the growth of cancer cells, arresting cell-cycle progression and inducing the mitochondrial pathway of apoptosis. Furthermore, Bcl-2-interacting mediator of cell death (Bim), a pro-apoptotic BH3-only member of the Bcl-2 family, may be involved in the regulation of apoptotic signaling.

\section{Materials and methods}

Reagents. DHA and 3-(4,5-dimethylthiazol-2-yl)-2,5-diphenyl tetrazolium bromide (MTT) were purchased from Sigma (Beijing, China). Stock solution of $100 \mathrm{mM}$ DHA was prepared in dimethylsulfoxide (DMSO) and diluted with complete DMEM medium before the experiments. The final concentration of DMSO was $<0.1 \%$. Rabbit anti-caspase- 8 polyclonal antibody was obtained from NeoMarkers, Inc. (Fremont, CA, USA). Antibodies against truncated Bid (tBid), cleaved-caspase-9 and cytochrome $c$ were purchased from Cell Signaling Technology (Beverly, MA, USA). Anti-human $\beta$-actin antibody was purchased from Sigma-Aldrich (St. Louis, MO, USA). Annexin V-FITC Apoptosis Detection kit was a product of BD Biosciences (Shenzhen, China).

Cell line and cell culture. Cell culture reagents were purchased from Invitrogen Corporation (Beijing, China) unless otherwise stated.The T-47Dhuman breast carcinomacellline was obtained from China Center for Type Culture Collection (CCTCC) and was maintained in DMEM supplemented with $10 \%$ fetal bovine serum (FBS), $100 \mathrm{U} / \mathrm{ml}$ penicillin and $100 \mathrm{mg} / \mathrm{ml}$ streptomycin in a humidified incubator with $5 \% \mathrm{CO}_{2}$ at $37^{\circ} \mathrm{C}$.

Cell growth assay. Effect of DHA on cell growth was measured by MTT assay. Briefly, T-47D cells were seeded in triplicate in 96 -well plates at $5 \times 10^{3}$ cells/well and left overnight to adhere. Subsequently, the medium was replaced with $200 \mu \mathrm{l}$ of fresh medium containing different concentrations of DHA $(0-100 \mu \mathrm{M})$, followed by incubation at $37^{\circ} \mathrm{C}$ and $5 \% \mathrm{CO}_{2}$ for 24,48 and $72 \mathrm{~h}$. After treatment, $10 \mu \mathrm{l}$ of MTT solution $(5 \mathrm{~g} / \mathrm{l})$ were added to each well for the last $4 \mathrm{~h}$. After 15 min of centrifuging at 2,000 rpm, culture medium was discarded and then replaced with $150 \mu \mathrm{DMSO} /$ well to dissolve the resultant formazan crystals. Absorbance (A) was measured with an enzyme-linked immunosorbent assay reader (Bio-Rad, USA) using $570 \mathrm{~nm}$ as test wavelength and $630 \mathrm{~nm}$ as reference wavelength. Results were representative of three individual experiments. Inhibition ratio $(\%)=(1$-experimental group $\mathrm{A}_{570-630}$ /control group $\mathrm{A}_{570-630}$ ) x100\%.

Cell cycle analysis. After treatment for $48 \mathrm{~h}$, cells were washed twice with cold phosphate buffered saline (PBS). Subsequently, cells were treated with PBS ( $\mathrm{pH}$ 7.4) containing $1 \% \mathrm{RNase}$, and were stained with propidium iodide (PI) at $100 \mathrm{mg} / \mathrm{ml}$ (final concentration). The percentages of cells in the $\mathrm{G} 0 / \mathrm{G} 1, \mathrm{~S}$ or $\mathrm{G} 2 / \mathrm{M}$ phase were calculated from a contour plot obtained for the flow cytometric analysis. The experiments were repeated at least three times independently.
Annexin V-FITC and PI apoptosis assay by flow cytometry. T-47D cells were plated at $2 \times 10^{5}$ in $60-\mathrm{mm}$ tissue culture dishes. Twenty-four hours later, the cells were treated with various concentrations of DHA for $48 \mathrm{~h}$. At the end of $48 \mathrm{~h}$, the cells were trypsinized and stained with the Annexin V-PI apoptosis detection kit as per the manufacturer's protocol. Finally, the stained cells were analyzed with a BeckmanCoulter flow cytometer. This assay distinguishes four groups of cells: dead cells (Annexin $\left./ \mathrm{PI}^{+}\right)$, normal living cells (Annexin $\left./ \mathrm{PI}^{-}\right)$, early apoptosis cells $\left(\right.$Annexin $\left.{ }^{+} / \mathrm{PI}^{-}\right)$, and late apoptosis cells $\left(\right.$ Annexin $\left.{ }^{+} / \mathrm{PI}^{+}\right)$. The apoptosis of T-47D cells was estimated by the relative amount of Annexin ${ }^{+} / \mathrm{PI}^{-}$of cell populations. Triplicate assays were performed.

Western blot analysis. T-47D cells from different treated groups were washed twice in ice-cold PBS and lysed in complete cell lysis buffer $(50 \mathrm{mM}$ Tris- $\mathrm{HCl}, \mathrm{pH} 7.4,150 \mathrm{mM}$ $\mathrm{NaCl}, 1 \%$ Triton X-100, 0.25\% Na-deoxycholate, 1 mM EDTA, $1 \mathrm{mM} \mathrm{NaF}, 1 \mathrm{mM}$ DTT, $1 \mathrm{mM}$ PMSF, $1 \mathrm{mM}$ activated $\mathrm{Na}_{3} \mathrm{VO}_{4}$, $1 \mu \mathrm{g} / \mathrm{ml}$ aprotinin, $1 \mu \mathrm{g} / \mathrm{ml}$ leupeptin, and $1 \mu \mathrm{g} / \mathrm{ml}$ pepstatin). Protein concentrations were determined using BCA assay (Hyclone-Pierce, USA). Protein samples were resolved on $10 \%$ SDS-PAGE and transferred to nitrocellulose membranes. The membranes were blocked in 5\% nonfat dry milk containing $0.1 \%$ Tween-20 at room temperature for $1 \mathrm{~h}$, and then probed with primary antibodies at $4{ }^{\circ} \mathrm{C}$ overnight. After washing, the membranes were incubated with horseradish peroxidase $(\mathrm{HRP})$-conjugated secondary antibody $(1: 8,000)$ followed by ECL detection (Amersham Pharmacia Biotech, Inc., USA). The membranes were scanned with a LAS-4000 luminescent image analyzer (Fujifilm, Japan). In the detection of cytochrome $c$, proteins in cytosolic fraction of cells were concentrated according to the method of Yuan et al (26) and the release of cytochrome $c$ from mitochondria to cytosol in apoptosis was detected.

Semi-quantitative RT-PCR detection. Total RNA was extracted from the cultured cells with TRIzol reagent (Invitrogen Corporation) according to the manufacturer's protocol. Firststrand cDNA was synthesized by MMLV Reverse Transcriptase (Promega Corporation). PCR was performed in $50 \mu \mathrm{l}$ volume. The primers were: Bim, forward, 5'-A TCT CAG AGC AAT GGC TT-3' and reverse, 5'-A TTC GTG GGT GGT CTT CG-3'; its amplification product was $163 \mathrm{bp}$. Bcl-2, forward, 5'-CGA CGA CTT CTC CCG CCG CTA CCG C-3' and reverse, 5'-CCG CAT GCT GGG GCC GTA CAG TTC C-3'; its amplification product was $318 \mathrm{bp}$. Human $\beta$-actin was used as internal control, forward, 5'-GTG GGG CGC CCC AGG CAC C-3' and reverse, 5'-CTC CTT AAT GTC ACG CAC GAT TT-3'; its amplification product was $506 \mathrm{bp}$. Amplification was performed under the following conditions: $95^{\circ} \mathrm{C}$ for $10 \mathrm{~min}$, followed by 30 cycles of $94^{\circ} \mathrm{C}$ for $30 \mathrm{sec}, 60^{\circ} \mathrm{C}$ for $30 \mathrm{sec}$ and $72^{\circ} \mathrm{C}$ for $1 \mathrm{~min}$, with a final extension of $10 \mathrm{~min}$ at $72^{\circ} \mathrm{C}$. DNA marker DL2000 (Takara Bio, Inc., Dalian, China) was used as standard. The relative mRNA expression of Bim, Bcl-2 was determined by normalizing to $\beta$-actin mRNA expression.

Statistical analysis. All experiments were performed in triplicate and data are presented as the means \pm standard deviation. Differences between groups were examined using the one-way 


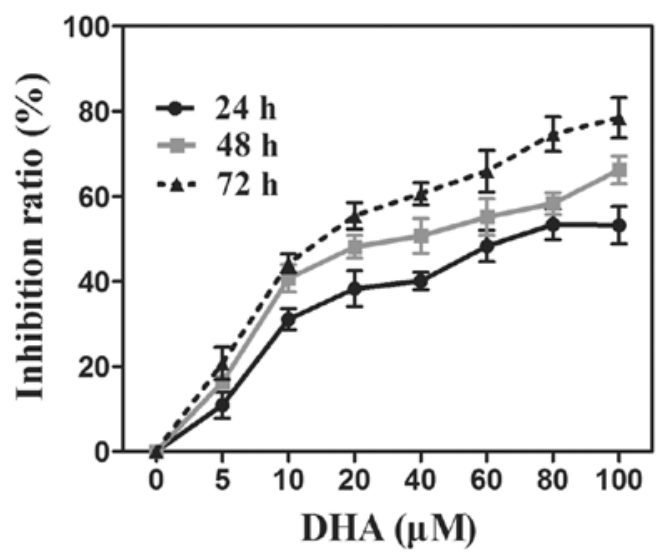

Figure 1. DHA attenuated the in vitro cell proliferation of breast cancer cells. T-47D cells were treated with various concentrations $(0-100 \mu \mathrm{M})$ of DHA for 24, 48 and $72 \mathrm{~h}$. The cell proliferation inhibition was detected using MTT growth assay. The results showed that DHA significantly inhibited the growth of T-47D cells in a dose-dependent $(\mathrm{r}=0.911, \mathrm{P}<0.01)$ and timedependent $(\mathrm{r}=0.918, \mathrm{P}<0.01)$ manner.

ANOVA or Student's t-test, when appropriate. All statistical tests were two-sided and a P-value of $<0.05$ was considered to indicate statistically significant differences.

\section{Results}

Cytotoxicity of DHA toward human breast cancer cells. We first evaluated the in vitro antitumor effect of DHA on the T-47D human breast cancer cells using the MTT assay. Cells were exposed to various concentrations $(0-100 \mu \mathrm{M})$ of DHA for 24,48 and $72 \mathrm{~h}$ and results showed that treatment with DHA had an obvious inhibitory effect in a dose-dependent $(\mathrm{r}=0.911$, $\mathrm{P}<0.01)$ and time-dependent manner $(\mathrm{r}=0.918, \mathrm{P}<0.01)$ (Fig. 1). The half maximal inhibitory concentration $\left(\mathrm{IC}_{50}\right)$ of DHA was detected to be $60.03,33.86$ and $17.18 \mu \mathrm{M}$ for 24,48 and $72 \mathrm{~h}$, respectively. These data indicated that DHA attenuated the in vitro proliferation of breast cancer cells.

DHA arrests cell cycle in breast cancer cells. To examine whether the cell growth inhibitory effect of DHA is induced via perturbation in cell cycle progression, we performed cellular DNA content distribution analysis by flow cytometric analysis. There were significant differences in proportions of G0/G1 and S phase between T-47D cells treated with DHA and no treatment control (Fig. 2A). The DHA treatment of different concentrations in breast cancer cells markedly increased the proportion of $\mathrm{G} 0 / \mathrm{G} 1$ phase and reduced the proportion of $\mathrm{S}$ phase, thereby preventing tumor cells entering DNA synthesis phase (Fig. 2B).

DHA induces apoptosis in breast cancer cells. Based on the above results, we further evaluated the pro-apoptotic activity of DHA. Results from Annexin V-PI analysis revealed that T-47D cells treated with DHA underwent obvious apoptosis compared to the control group in a dose-dependent manner. The apoptotic ratio was increased to $20.67 \pm 6.53 \%, 30.30 \pm 3.71 \%$ and $45.57 \pm 9.16 \%$, respectively, after DHA treatment, at the concentration of 20,40 and $60 \mu \mathrm{M}$ for $48 \mathrm{~h}$ (Fig 3). There were significant differences compared with control of $2.47 \pm 1.21 \%$ $(\mathrm{P}<0.01, \mathrm{P}<0.001$ and $\mathrm{P}<0.001$, respectively).

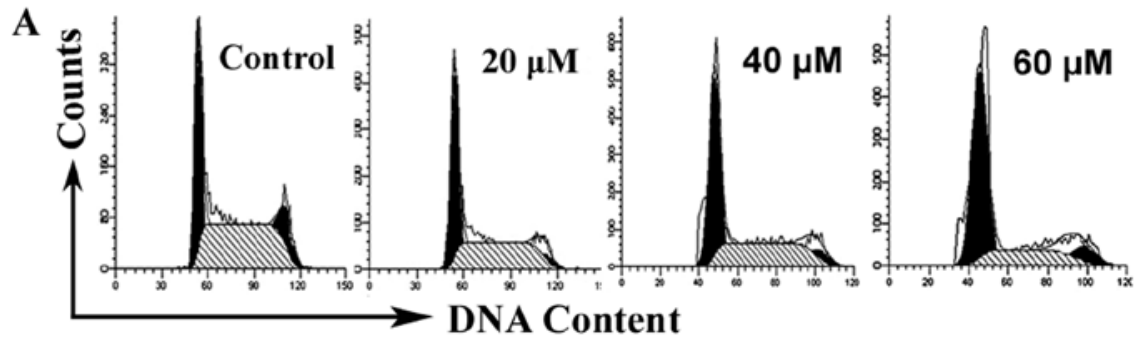

B

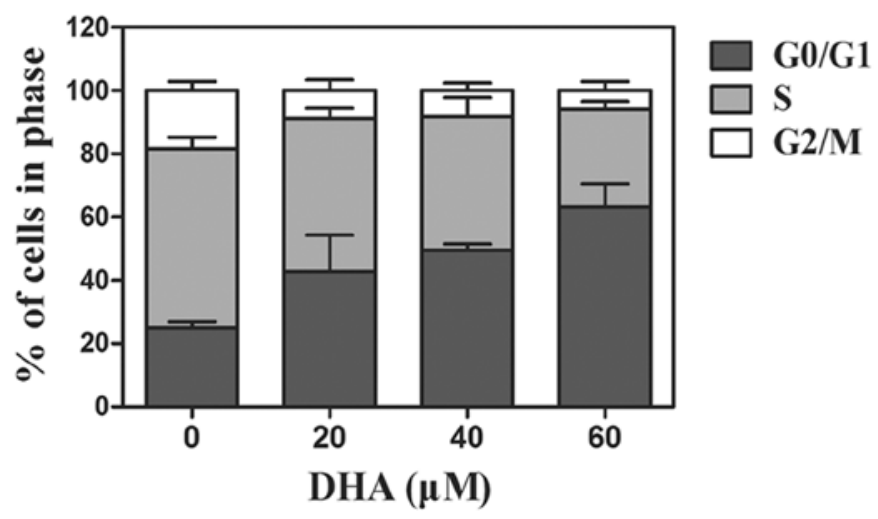

Figure 2. DHA induced cell cycle arrest in breast cancer cells. (A) Cells were treated with different concentrations of DHA for 48 h. DNA content analysis by flow cytometry showed the percentages of cells in the G0/G1, synthetic or G2/M phases of the cell cycle. A representative image of flow cytometry is depicted. (B) Quantitative analysis of cells in each cell cycle phase was performed. The results demonstrated that DHA treatment of different concentrations in breast cancer cells clearly induced G0/G1 phase arrest and prevented tumor cells entering DNA synthesis phase, and thereby inhibited the proliferation of tumor cells. The experiment was repeated three times in triplicate. 

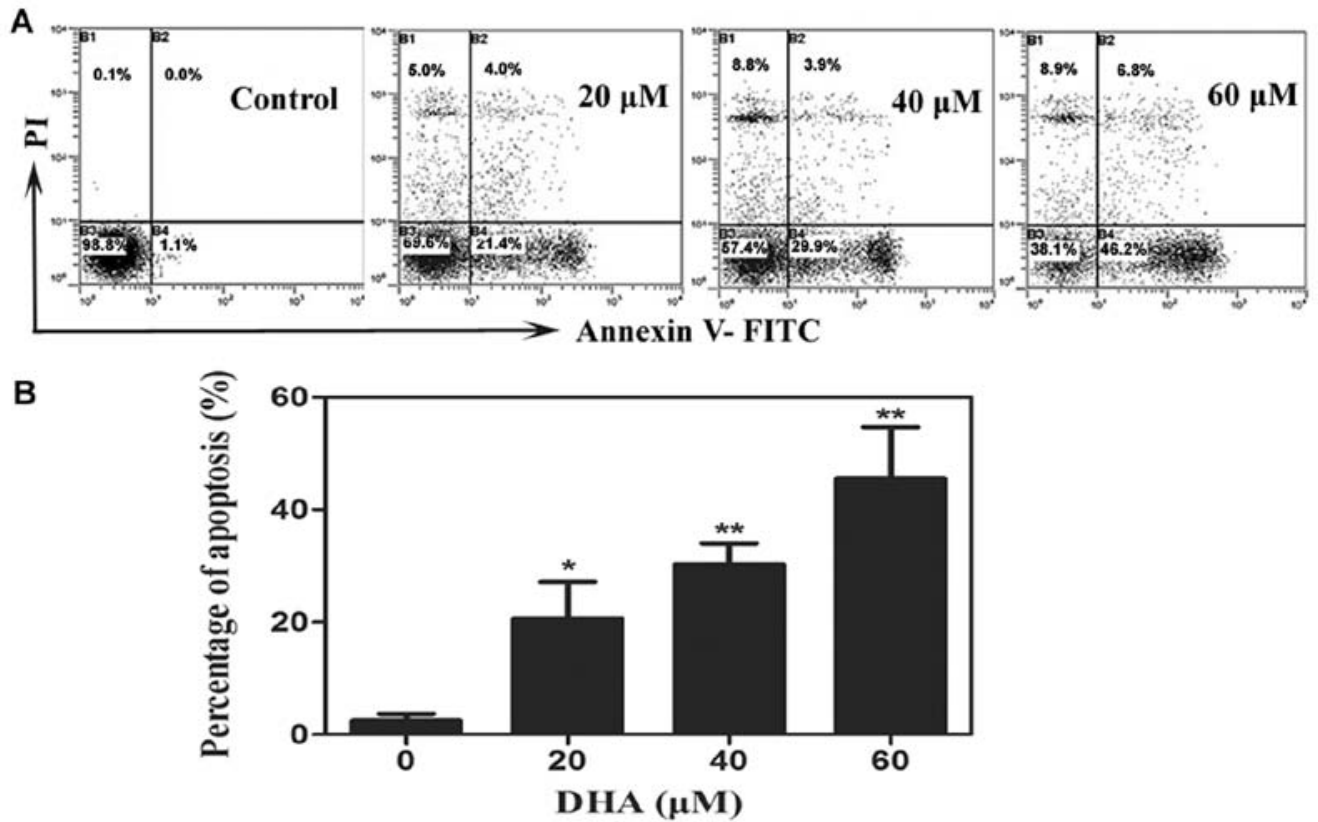

Figure 3. DHA induced apoptosis in breast cancer cells. (A) Apoptosis was detected by flow cytometry as described in Materials and methods. Annexin V conjugated to FITC allows the identification of apoptotic cells. A representative apoptosis result is presented. (B) The DHA treatment further induced apoptosis as compared with control in a dose-dependent manner. All experiments were performed three times independently. ${ }^{*} \mathrm{P}<0.01,{ }^{* *} \mathrm{P}<0.001$, compared with the control group.

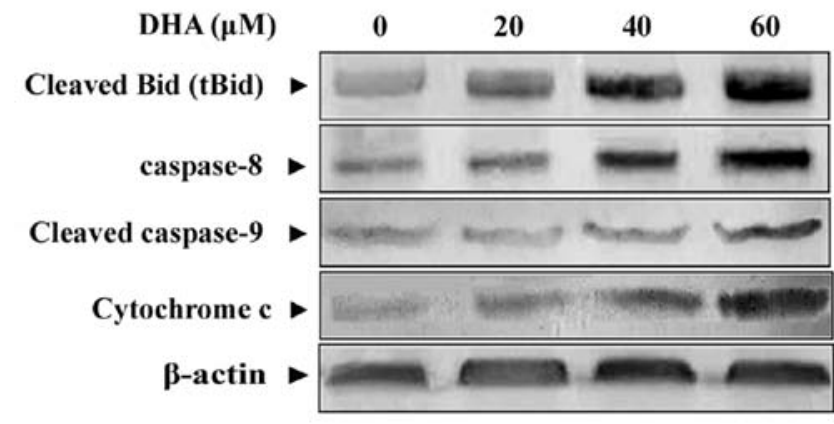

Figure 4. Western blot analysis of apoptosis-related proteins. T-47D cells were treated with DHA at 20, 40 and $60 \mu \mathrm{M}$ for $48 \mathrm{~h}$. Effects of apoptosis-related proteins in response to DHA treatment were assessed by western blot analysis. The expression levels of caspase-8, cleaved caspase-9, tBid and cytochrome $c$ were clearly increased by the DHA treatment in a dose-dependent manner. The protein levels were normalized against a $\beta$-actin level that was used as an internal control. Experiments were performed three times independently.

DHA increases the expression of apoptosis-related proteins. To define the apoptotic pathway(s) being activated by DHA, we examined the status of activation of several critical apoptosis-related factors. Western immunoblotting was employed to detect the activation of caspase- 8 , and -9 , Bid and cytochrome $c$ released into the cytosolic fractions. Fig. 4 shows that caspase- 8 , cleaved caspase- 9 and the active, truncated form of Bid (tBid) were activated in response to DHA. Moreover, following stimulation with DHA, cytochrome $c$ was released from mitochondria into cytosol and resulted in a dramatic increase of cytochrome $c$ protein concentration, indicating the involvement of the mitochondrial apoptotic pathway.

DHA regulates Bim and Bcl-2 expression. Bim, as a proapoptotic gene of the Bcl-2 family, has been considered to play
A

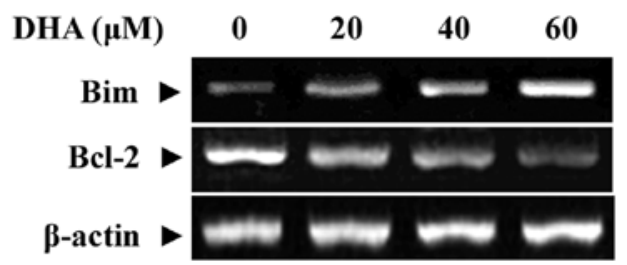

B

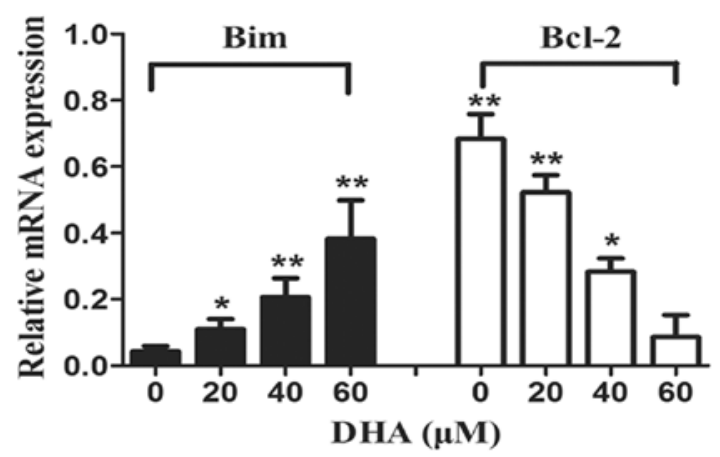

Figure 5. Expression of Bim and Bcl-2 mRNA by RT-PCR. T-47D cells were treated with DHA at 20,40 and $60 \mu \mathrm{M}$ for $48 \mathrm{~h}$ and the expression of Bim and Bcl-2 mRNA was assessed. (A) Electrophotogram of amplification product. $\beta$-actin gene amplification (506 bp) was carried out as internal control. (B) Semi-quantity analysis of Bim and Bcl-2 mRNA. DHA treatment markedly increased the expression of Bim mRNA and decreased the expression of Bcl-2 mRNA in breast cancer cells. Results represent mean values of three experiments $\pm \mathrm{SD} .{ }^{*} \mathrm{P}<0.05,{ }^{* *} \mathrm{P}<0.01$, compared with the control group.

an important role in initiating the mitochondrial apoptotic pathway by binding to anti-apoptotic Bcl-2 and sequestering it from pro-apoptotic proteins. To further investigate the underlying mechanism of the apoptosis mediated by DHA, we performed RT-PCR analysis to detect the change of Bim and Bcl-2 mRNA level. There was increased Bim expression in 
DHA treatment groups of different concentrations compared to no treatment control in a dose-dependent manner (Fig. 5A). Furthermore, the marked decrease of mRNA expression at the $\mathrm{Bcl}-2$ gene was induced $(\mathrm{P}<0.05$ and $\mathrm{P}<0.01$, respectively).

\section{Discussion}

Among various anticancer candidates, the natural product artemisinin and its derivatives, particularly DHA, have been found to display powerful anticancer activity in several types of tumors. Cancer cells have been shown to be much more sensitive to DHA than their normal counterparts $(8,19,27)$. However, the molecular details of DHA-induced cytotoxic effects remain unclear. The present in vitro study was conducted in an effort to explore the potential mechanisms of DHA treatment as a novel anticancer drug for breast cancer. The growth assay of T-47D breast cancer cells treated with DHA was detected in this study. The results from MTT assay suggested that DHA was able to suppress the proliferation of breast cancer cells in a dose- and time-dependent manner. The molecular mechanism behind this inhibition has been explored in previous studies. It has been reported that DHA inhibited Akt and ERK activation and, thus, appeared to mediate its effect partly via inhibition of the PI3-K/ Akt and ERK pathways, the two major cell proliferation and survival pathways (13). Another study found that the proliferation inhibitory effect of DHA was related to the expression of proliferating cell nuclear antigen (PCNA) (28). PCNA is synthesized during the early G1 and S phases of the cell cycle and is involved in the uncontrollable proliferation of cancer cells by assisting DNA replication and base excision repair (29). PCNA was clearly downregulated by DHA in pancreatic cancer in a dose-dependent manner (28). This result was also supported by our own observation and other studies $(30,31)$ that the treatment of DHA delayed the cell cycle and induced a marked reduction of $\mathrm{S}$ phase and accumulation of G0/G1 phase.

In addition to the antiproliferative effect and cell cycle arrest on breast cancer cells, DHA was also shown to induce apoptosis in a dose-dependent manner in our study. Apoptosis is one of the major mechanisms of cell death in response to cancer therapies. Two major apoptosis pathways have been defined in a number of different cell types; the first is the death receptor pathway initiated mainly by tumor necrosis factor receptors (TNFRs) and Fas and the second is termed the mitochondrial apoptotic pathway and involves mitochondria and Bcl-2 family members. Caspase- 8 is an important apoptosis protein that is activated initially in both the death receptor and the mitochondrial pathway. In the current study, caspase- 8 was strongly upregulated by DHA treatment. Sequentially, caspase- 8 activated Bid, a pro-apoptotic Bcl-2 family protein. As shown in this study, the DHA action enhanced the activation of tBid (active form of Bid that is capable of triggering apoptosis) significantly and induced mitochondrial damage, cytochrome $c$ release and caspase- 9 activation. Activation of caspase-9 then triggered the downstream effector caspase cascade, resulting in the apoptosis of cells. As an apo-protein, cytochrome $c$ is nearly undetectable in the cytosol in normal cells. However, the release of cytochrome $c$ from mitochondria to cytosol can be induced in apoptosis when the mitochondrial pathway is involved (32). We measured the expression of cytochrome $c$ in cytosolic fractions and the data revealed a significant upregulation of cytochrome $c$ expression in cytoplasm in DHA-exposed breast cancer cells. A previous study also demonstrated that DHA treatment markedly lowered the mitochondrial transmembrane potential, resulting from mitochondrial membrane depolarization and the release of cytochrome $c$ from mitochondria to cytoplasm in human hepatocellular carcinoma cells (21). Based on the above data, we concluded that DHA induced apoptosis in breast cancer cells via the mitochondrial pathway.

To date, two protein families are known to be crucial in the process of apoptosis: one is the Bcl-2 family as a decisionmaker of apoptosis; the other is the caspase family, which is an executor of apoptosis. Bcl-2 family members include antiapoptotic (Bcl-2, Bcl-xL) and pro-apoptotic proteins (Bax, Bak, Bid, Bim and Bad) and they tightly control the activation of the mitochondrial apoptotic pathway by regulating mitochondrial homeostasis and permeability (33). As a pro-apoptotic BH3-only member of the Bcl-2 family, Bim plays a key role in the initiation of apoptosis induced by a broad range of cytotoxic stimuli. Bim is required for apoptosis of autoreactive thymocytes and neurons and a Bim/Bcl-2 balance is critical for controlling normal homeostasis of naïve and memory T cells (34-36). It has been established that Bim can induce apoptosis by engaging both anti- and pro-apoptotic family members at mitochondria. Recent studies have also confirmed that Bim interacts with and embeds Bcl-2 in mitochondrial membranes. Subsequently, Bcl-2 and Bim form oligomers that permeabilize the mitochondrial outer membrane to release cytochrome $c$ and activate caspases $(35,37)$. In the current study, we further investigated whether Bim and Bcl-2 were involved in DHA-induced apoptosis as an upstream messenger, so that we could better elucidate the molecular mechanisms of the observed cell apoptosis. Here, we found that DHA-induced apoptosis was accompanied by an increase of Bim and a decrease of Bcl-2. Based on previous studies and our own observations, we deduced that the Bim/Bcl-2 interaction may be involved in the apoptotic effect induced by DHA. DHA treatment upregulated pro-apoptotic Bim expression and downregulated anti-apoptotic Bcl-2 expression, and thereby led to the imbalance of the $\mathrm{Bim} / \mathrm{Bcl}-2$ interaction. Abundant Bim either bound to $\mathrm{Bcl}-2$ proteins and formed oligomers to induce cytochrome $c$ release, or activated Bax/Bak directly to initiate the mitochondrial cell death pathway. The validity of this assumption and the mechanism underlying the upregulation of Bim remain to be verified in future studies.

In summary, we have confirmed that the natural plant drug DHA exerts its anticancer effects by inhibiting proliferation, arresting cell cycle and promoting the apoptosis of tumor cells. Moreover, the mitochondrial pathway is involved in the apoptosis of breast cancer cells induced by DHA and Bim/Bcl-2 may be responsible for DHA-induced apoptosis. These cellular effects, in combination with relatively low toxicity in humans, make DHA an attractive candidate drug for the treatment of breast cancer.

\section{Acknowledgements}

This study was supported by the National Natural Science Foundation of China (31270970), the Science and Technology Project of Shandong, China (2008GG10002035, 2012G0021821) and the Science and Technology Project of Jinan, China (201202197). 


\section{References}

1. Jemal A, Bray F, Center MM, Ferlay J, Ward E and Forman D: Global cancer statistics. CA Cancer J Clin 61: 69-90, 2011.

2. Antoon JW, Lai R, Struckhoff AP, et al: Altered death receptor signaling promotes epithelial-to-mesenchymal transition and acquired chemoresistance. Sci Rep 2: 539, 2012.

3. White NJ: Qinghaosu (artemisinin): the price of success. Science 320: 330-334, 2008.

4. German PI and Aweeka FT: Clinical pharmacology of artemisinin-based combination therapies. Clin Pharmacokinet 47: 91-102, 2008

5. Efferth T: Willmar Schwabe Award 2006: antiplasmodial and antitumor activity of artemisinin - from bench to bedside. Planta Med 73: 299-309, 2007.

6. Efferth T, Dunstan H, Sauerbrey A, Miyachi H and Chitambar CR: The anti-malarial artesunate is also active against cancer. Int J Oncol 18: 767-773, 2001.

7. Klayman DL: Qinghaosu (artemisinin): an antimalarial drug from China. Science 228: 1049-1055, 1985.

8. Disbrow GL, Baege AC, Kierpiec KA, et al: Dihydroartemisinin is cytotoxic to papillomavirus-expressing epithelial cells in vitro and in vivo. Cancer Res 65: 10854-10861, 2005.

9. Hosoya K, Murahari S, Laio A, London CA, Couto CG and Kisseberth WC: Biological activity of dihydroartemisinin in canine osteosarcoma cell lines. Am J Vet Res 69: 519-526, 2008

10. Mercer AE, Copple IM, Maggs JL, O'Neill PM and Park BK The role of heme and the mitochondrion in the chemical and molecular mechanisms of mammalian cell death induced by the artemisinin antimalarials. J Biol Chem 286: 987-996, 2011.

11. Zhang S and Gerhard GS: Heme mediates cytotoxicity from artemisinin and serves as a general anti-proliferation target. PLoS One 4: e7472, 2009.

12. Toovey S, Bustamante LY, Uhlemann AC, East JM and Krishna S: Effect of artemisinins and amino alcohol partner antimalarials on mammalian sarcoendoplasmic reticulum calcium adenosine triphosphatase activity. Basic Clin Pharmacol Toxicol 103: 209-213, 2008.

13. Handrick R, Ontikatze T, Bauer KD, et al: Dihydroartemisinin induces apoptosis by a Bak-dependent intrinsic pathway. Mol Cancer Ther 9: 2497-2510, 2010.

14. Eckstein-Ludwig U, Webb RJ, Van Goethem ID, et al: Artemisinins target the SERCA of Plasmodium falciparum. Nature 424 957-961, 2003.

15. Chen T, Li M, Zhang R and Wang H: Dihydroartemisinin induces apoptosis and sensitizes human ovarian cancer cells to carboplatin therapy. J Cell Mol Med 13: 1358-1370, 2009.

16. Wang SJ, Gao Y, Chen H, et al: Dihydroartemisinin inactivates NF-kappaB and potentiates the anti-tumor effect of gemcitabine on pancreatic cancer both in vitro and in vivo. Cancer Lett 293: 99-108, 2010.

17. Chen M, Chen TS, Lu YY, Liu CY and Qu JL: Dihydroarteminsinin-induced apoptosis is not dependent on the translocation of Bim to the endoplasmic reticulum in human lung adenocarcinoma cells. Pathol Oncol Res 18: 809-816, 2012.

18. He Q, Shi J, Shen XL, et al: Dihydroartemisinin upregulates death receptor 5 expression and cooperates with TRAIL to induce apoptosis in human prostate cancer cells. Cancer Biol Ther 9: 819-824, 2010.

19. Singh NP and Lai H: Selective toxicity of dihydroartemisinin and holotransferrin toward human breast cancer cells. Life Sci 70: 49-56, 2001.
20. Singh NP and Lai HC: Synergistic cytotoxicity of artemisinin and sodium butyrate on human cancer cells. Anticancer Res 25: 4325-4331, 2005

21. Zhang CZ, Zhang H, Yun J, Chen GG and Lai PB: Dihydroartemisinin exhibits antitumor activity toward hepatocellular carcinoma in vitro and in vivo. Biochem Pharmacol 83: 12781289, 2012.

22. Huang XJ, Ma ZQ, Zhang WP, Lu YB and Wei EQ: Dihydroartemisinin exerts cytotoxic effects and inhibits hypoxia inducible factor-1alpha activation in C6 glioma cells. J Pharm Pharmacol 59: 849-856, 2007.

23. Mercer AE, Maggs JL, Sun XM, et al: Evidence for the involvement of carbon-centered radicals in the induction of apoptotic cell death by artemisinin compounds. J Biol Chem 282: 9372 9382, 2007.

24. Gao N, Budhraja A, Cheng S, et al: Interruption of the MEK/ ERK signaling cascade promotes dihydroartemisinin-induced apoptosis in vitro and in vivo. Apoptosis 16: 511-523, 2011

25. Reungpatthanaphong $\mathrm{P}$ and Mankhetkorn S: Modulation of multidrug resistance by artemisinin, artesunate and dihydroartemisinin in K562/adr and GLC4/adr resistant cell lines. Biol Pharm Bull 25: 1555-1561, 2002.

26. Yuan J, Murrell GA, Trickett A and Wang MX: Involvement of cytochrome $\mathrm{c}$ release and caspase- 3 activation in the oxidative stress-induced apoptosis in human tendon fibroblasts. Biochim Biophys Acta 1641: 35-41, 2003.

27. Noori S and Hassan ZM: Dihydroartemisinin shift the immune response towards Th1, inhibit the tumor growth in vitro and in vivo. Cell Immunol 271: 67-72, 2011.

28. Aung W, Sogawa C, Furukawa T and Saga T: Anticancer effect of dihydroartemisinin (DHA) in a pancreatic tumor model evaluated by conventional methods and optical imaging. Anticancer Res 31: 1549-1558, 2011.

29. Kelman Z: PCNA: structure, functions and interactions. Oncogene 14: 629-640, 1997.

30. Lu JJ, Chen SM, Ding J and Meng LH: Characterization of dihydroartemisinin-resistant colon carcinoma HCT116/R cell line. Mol Cell Biochem 360: 329-337, 2012.

31. Morrissey C, Gallis B, Solazzi JW, et al: Effect of artemisinin derivatives on apoptosis and cell cycle in prostate cancer cells. Anticancer Drugs 21: 423-432, 2010.

32. Renz A, Berdel WE, Kreuter M, Belka C, Schulze-Osthoff K and Los M: Rapid extracellular release of cytochrome $\mathrm{c}$ is specific for apoptosis and marks cell death in vivo. Blood 98: 1542-1548, 2001.

33. Youle RJ and Strasser A: The BCL-2 protein family: opposing activities that mediate cell death. Nat Rev Mol Cell Biol 9: 47-59, 2008.

34. Bouillet P, Purton JF, Godfrey DI, et al: BH3-only Bcl-2 family member Bim is required for apoptosis of autoreactive thymocytes. Nature 415: 922-926, 2002.

35. Zhao L, He F, Liu H, et al: Natural diterpenoid compound elevates expression of Bim protein, which interacts with antiapoptotic protein Bcl-2, converting it to proapoptotic Bax-like molecule. J Biol Chem 287: 1054-1065, 2012.

36. Wojciechowski S, Tripathi P, Bourdeau T, et al: Bim/Bcl-2 balance is critical for maintaining naive and memory $\mathrm{T}$ cell homeostasis. J Exp Med 204: 1665-1675, 2007.

37. Willis SN, Fletcher JI, Kaufmann T, et al: Apoptosis initiated when BH3 ligands engage multiple Bcl-2 homologs, not Bax or Bak. Science 315: 856-859, 2007. 